\title{
Hypoxia, metabolism, and the circadian clock: new links to overcome radiation resistance in high-grade gliomas
}

\author{
Han Shen ${ }^{1,2^{*}+}$, Kristina Cook ${ }^{2,3 \dagger}$, Harriet E. Gee ${ }^{1,2,4}$ and Eric Hau ${ }^{1,2,4,5}$
}

\begin{abstract}
Radiotherapy is the cornerstone of treatment of high-grade gliomas (HGGs). It eradicates tumor cells by inducing oxidative stress and subsequent DNA damage. Unfortunately, almost all HGGs recur locally within several months secondary to radioresistance with intricate molecular mechanisms. Therefore, unravelling specific underlying mechanisms of radioresistance is critical to elucidating novel strategies to improve the radiosensitivity of tumor cells, and enhance the efficacy of radiotherapy. This review addresses our current understanding of how hypoxia and the hypoxia-inducible factor 1 (HIF-1) signaling pathway have a profound impact on the response of HGGs to radiotherapy. In addition, intriguing links between hypoxic signaling, circadian rhythms and cell metabolism have been recently discovered, which may provide insights into our fundamental understanding of radioresistance. Cellular pathways involved in the hypoxic response, DNA repair and metabolism can fluctuate over 24-h periods due to circadian regulation. These oscillatory patterns may have consequences for tumor radioresistance. Timing radiotherapy for specific times of the day (chronoradiotherapy) could be beneficial in patients with HGGs and will be discussed.
\end{abstract}

Keywords: Radiotherapy, Hypoxia, Circadian rhythm, High-grade glioma, Metabolism

\section{Background}

HGGs are diagnosed in patients of all ages, including children. Glioblastoma, the most aggressive HGG, typically occurs between 45 and 75 years of age and carries a dismal prognosis of less than 15 months. Surgery and radiotherapy have been the cornerstone of treatment for glioblastoma. To improve the poor outcomes associated with this disease, numerous therapeutics have been added to radiotherapy without success until the landmark study established a standard of care with gross surgical excision followed by concurrent temozolomide and

\footnotetext{
* Correspondence: han.shen@sydney.edu.au

${ }^{\dagger} \mathrm{Han}$ Shen and Kristina Cook contributed equally to this work.

${ }^{1}$ Translational Radiation Biology and Oncology Laboratory, Centre for Cancer Research, Westmead Institute for Medical Research, Westmead, New South Wales 2145, Australia

${ }^{2}$ Sydney Medical School, University of Sydney, Camperdown, New South Wales, Australia

Full list of author information is available at the end of the article
}

radiotherapy [1]. While gains have been made in understanding glioblastoma biology, improving patient outcome remains a significant challenge. Although the addition of temozolomide has modest overall survival benefit in patients with methylated MGMT promoter, it confers little benefit in the $60 \%$ of glioblastoma patients with unmethylated $M G M T$ promoter [2]. In children, the incidence of HGGs is much lower, but they similarly have a very poor prognosis overall, with treatment consisting of maximal surgical resection followed by radiotherapy. The role of temozolomide is less clear in pediatric high-grade gliomas (pHGGs) as compared to glioblastoma. Among all the pHGGs, diffuse intrinsic pontine glioma (DIPG) is the most aggressive form arising from the centre of the brainstem, the most critical area of the brain. As a result, surgical resection is impossible, and in most cases even a biopsy is hazardous. 
During the past decade, clinical trials of chemotherapeutic agents and targeted therapies in DIPG have not shown any survival benefit, and radiotherapy is the only standard treatment [3].

Radiotherapy is the targeted administration of X-rays to destroy cancer cells and tumor tissue. It targets rapidly proliferating tumor cells by inducing oxidative stress through increased Reactive Oxygen Species (ROS). With active oxygen molecules including superoxide and hydroxyl radicals, ROS break chemical bonds and activate the cascade in DNA damage and subsequent cell death. During this process, oxygen is critical to stabilize the DNA damage induced by ROS, and this forms the basic mechanism by which radiation is used in cancer treatment [4]. Hypoxia, a common characteristic of most solid tumors, prevents the fixation of DNA damage by oxygen, thus being a major cause of radioresistance in cancer treatment [5]. Furthermore, hypoxia activates the hypoxia-inducible factor 1 (HIF-1) pathway which favors the survival of tumor cells by increasing their glucose uptake and utilization via altered glucose metabolism [6]. It also induces angiogenesis [7], creates an acidic microenvironment and promotes proliferation [8], all of which collectively dampen the efficacy of radiotherapy (Fig. 1). HIF-1 is also well known to be expressed constitutively in cancer cells under normoxic conditions through cancer-specific genetic alterations [9]. Radiotherapy, on the other hand, has also been reported to stabilize HIF-1 signaling via radiation-induced reoxygenation, ROS elevation and microvascular destruction, leading to the development of acquired radioresistance [10]. Interestingly, the dysregulation of circadian rhythm has also recently been identified as a characteristic contributing to growth, stemness and metabolic changes observed in HGGs [11] (Fig. 2). The circadian rhythm disorder modulated by HIF-1 signaling may even further affect the radiosensitivity of tumor cells. In this review, we summarize and discuss how the HIF-1 pathway impacts on radioresistance of solid tumors with a focus on HGGs, via modifying glucose metabolism and circadian rhythm of tumor cells. Furthermore, inhibition of HIF-1 modulated glucose metabolism and circadian rhythm is also discussed as a potential approach to overcoming radioresistance of HGGs in both adult and pediatric settings.

\section{Radioresistance of HGG cells}

Irradiation as a cancer therapy, was discovered over twelve decades ago and has become the cornerstone of treatment for many types of cancer. For HGGs, radiotherapy is either given as definitive treatment for inoperable tumors or delivered post-surgery to the area of the excision to kill residual tumor cells. The effectiveness of radiotherapy relies mainly on its ability to cause lethal damage to the DNA of cancer cells, with contributions from damage to sub-cellular organelles, and triggers cell

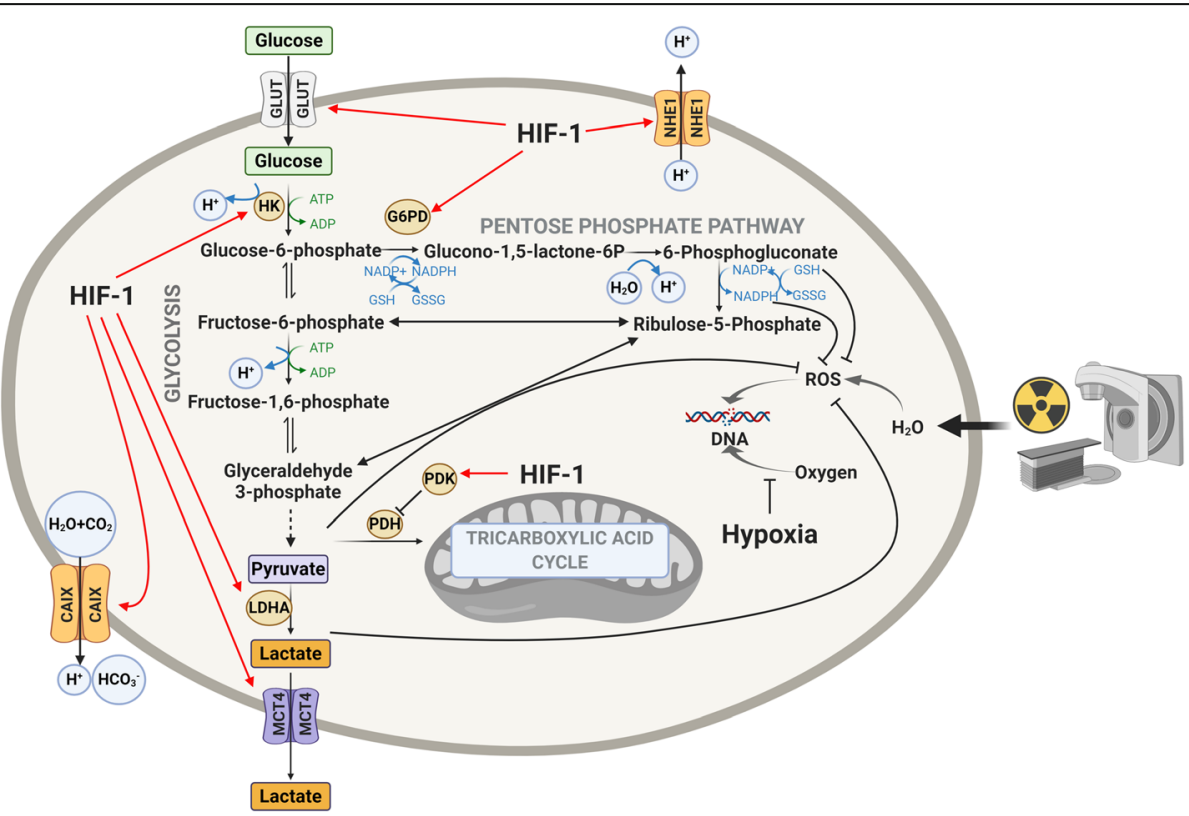

Fig. 1 The mechanism of actions whereby the hypoxia inducible factor (HIF-1) regulates glycolysis, lactate pathway and pentose phosphate pathways in radioresistance. ADP, adenosine diphosphate; ATP,adenosine triphosphate; CAIX, carbonic anhydrase 9; G6PD, glucose-6-phosphate dehydrogenase; GLUT, glucose transporters; GSH, glutathione; GSSG, glutathione disulfide; HIF-1, hypoxia inducible factor-1; HK, hexokinase; LDHA, lactate dehydrogenase $\mathrm{A} ; \mathrm{MCT} 4$, monocarboxylate transporter 4; NHE1, Na+/H+ exchanger isoform 1; PDH, pyruvate dehydrogenase; PDK, pyruvate dehydrogenase kinase; ROS, reactive oxygen species 


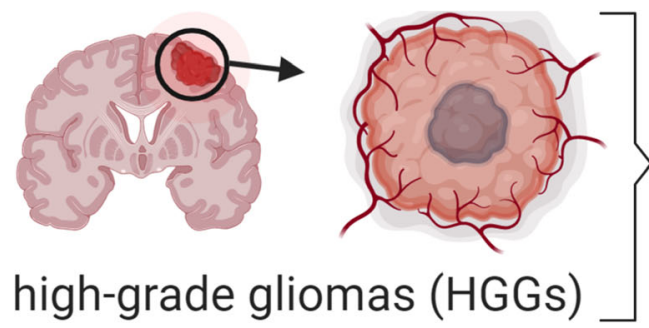

$\uparrow \mathrm{HIF}$

$\uparrow$ glycolysis

$\uparrow$ radioresistance $\uparrow$ circadian dysregulation

Fig. 2 High-grade gliomas (HGGs) have multiple characteristics that contribute to their aggressive behavior. Increased levels of HIF, glycolysis and radioresistance are common. Circadian dysregulation has also been identified as a recent characteristic contributing to growth, stemness and metabolic changes observed in HGGs

death by inducing cellular stress response and activating intracellular signaling pathways resulting in cell death [12]. Although radiotherapy is one of the most effective therapies for cancer treatment, most malignant tumors inevitably relapse secondary to radioresistance. This is particularly true for HGGs due to the high intrinsic radioresistance of glioma cells, especially in the presence of glioma stem cells (GSCs) that are enriched in the hypoxic niche [13]. Radioresistance is a process in which either the intrinsically radioresistant cells are selected for by radiotherapy or the surviving tumor cells adapt and develop acquired resistance due to the radiotherapyinduced changes. This is an intricate process involving multiple mechanisms which remain to be fully elucidated. Hitherto, both pre-clinical and clinical studies have revealed some of the mechanisms underlying this phenomenon, including changes in capability of DNA repair, cell cycle arrest, alterations of gene expression, changes in microenvironment, induction of autophagy, generation of cancer stem cells, and rewiring of metabolic pathways [14-16]. In the following section, we will primarily focus on metabolic reprogramming, one of the hallmarks of cancer, because most of those aforementioned machineries converge in a common adaptation of tumor cell metabolism that is strongly linked to radioresistance in cancer treatment.

\section{Role of hypoxia, HIF signaling mediated glucose metabolism and radiotherapy in radioresistance of HGGs}

Hypoxia in HGGs Hypoxia, or physiologically low levels of oxygen tension, develops in HGGs from uncontrollable cell proliferation and dysfunctional vascularization. In patients with a malignant solid tumor, hypoxia is strongly correlated with a poor prognosis, an increased chance of metastasis and resistance to chemoradiotherapy [17]. It is generally accepted that the oxygen level in hypoxic tumor tissues is much lower than that in their corresponding normal tissues and on average it is below $1-2 \% \mathrm{O}_{2}(\mathrm{v} / \mathrm{v})$ [18]. In glioblastoma, the hypercellular zones, referred to as 'pseudopalisading necrosis', typically surrounding necrotic foci are constantly exposed to moderate hypoxia [19]. Hypoxia in glioblastoma has been observed by magnetic resonance imaging (MRI) where reduced oxygen diffusion is detected, consistent with restricted blood flow [20]. Molecular markers of hypoxia, such as HIF-1 and its downstream targets vascular endothelial growth factor (VEGF) and carbonic anhydrase 9 (CA IX), are consistently detected in glioblastoma using immunohistochemistry staining [21], while dynamic contrast enhanced MRI reveals tumor vascularity [22]. These features correlate with worse progression-free and overall survival [23, 24]. Although hypoxia is a well-known characteristic in adult HGGs, its role in pHGGs remains relatively less known. Genomics and metabolomics data from a recent study support hypoxia as an important key to preserve the abnormal metabolism of pHGG cells and cell dissemination present in pHGG patients [25]. In addition, DIPGs in the brainstem have been detected with low blood perfusion and regions of necrosis by using MR spectroscopy, indicative of a hypoxic environment that supports activation of HIF, which is associated with increased proliferation, invasion and therapy resistance [26].

HIF-1a mediated reprogramming of glucose metabolism and radioresistance Hypoxia induces transcriptomic changes followed by proteomic alteration within tumor cells. At the molecular level, the adaptation of tumor cells to reduced oxygen tension is regulated mainly by HIF, a transcription factor which stabilizes in response to reduced oxygen levels. In the human HIF family, there are three isoforms, HIF-1, HIF2 and HIF-3, all of which are heterodimers comprising of $\alpha$ and $\beta$ subunits. Of these three members, HIF- $1 \alpha$ is frequently overexpressed in tumor cells, and is the most extensively studied in cancer research. HIF- $1 \alpha$ is ubiquitously expressed throughout tissues in the body, while the HIF- $2 \alpha$ and HIF-3 $\alpha$ isoforms are only expressed in select tissues (including the brain) and are not as well studied. 
The transcription of genes that encode glucose transporters and enzymes regulating glycolysis and the pentose phosphate pathway (PPP) is extensively regulated by HIF-1 $\alpha$ [27] (Fig. 1). As hypoxia suppresses the activities of the key enzymes controlling the rate of tricarboxylic acid cycle, tumor cells switch to glycolysis for energy production [28]. Pyruvate, lactate, and hydrogen ions are abundantly produced in anaerobic glycolysis or the Pasteur effect [29]. In contrast to the Pasteur effect, a hallmark of cancer cells is a high rate of glucose consumption and lactate generation even in the presence of ample oxygen. This distinctive metabolic feature of cancer cells was first observed in the 1920s by Otto Warburg [30], referred to as the Warburg effect. With the Warburg effect, cancer cells heavily rely on the glycolytic pathway to support their energy demands under normoxia [31]. This is also supported by later studies showing the constitutive expression of HIF- $1 \alpha$ in many cancer cell lines independent of hypoxic circumstances [32]. Although the glycolytic phenotype may seem counterintuitive due to the less efficient ATP production by glycolysis compared with oxidative phosphorylation, studies have revealed the use of glycolysis by cancer cells provides a growth advantage and facilitates malignant progression [31]. For example, the glycolytic intermediate glucose-6-phosphate (G-6-P) is also used in the PPP, which synthesizes precursors of nucleotides and amino acids required for tumor cell growth and proliferation.

HGGs, like most malignant solid tumors, are highly glycolytic, producing large amounts of lactate as a metabolic by-product [33]. It has been shown that tumors with high levels of glycolysis are less responsive to chemoradiotherapy and behave more aggressively [34]. More recent reports have also identified the Warburg effect to be implicated in resistance to oxidative stress induced by radiotherapy [35]. Since G-6-P serves as a substrate for the PPP responsible for the biogenesis of the antioxidants NADPH and glutathione [36], the HIF$1 \alpha$-mediated Warburg effect has been associated with the increased antioxidant capacity of tumor cells and eventual radioresistance [37]. A very recent study reported TP53 mutation as the main driver of increased radioresistance in both patients and corresponding cellular models of DIPG [38]. TP53 is known to impact glycolysis through several mechanisms including transcriptionally repressing the expression of glucose transporters, down-regulating rate limiting enzymes of glycolysis, decreasing the expression of transporters responsible for lactate extrusion and negatively regulating the AKT/mTOR [39] and NF- $\mathrm{KB}$ signaling pathways [40]. It can also modulate expression of glycolytic enzymes like phosphoglycerate mutase and TP53-induced glycolysis and apoptosis regulator (TIGA R), a stimulator of gluconeogenesis and the PPP [41].
These findings collectively indicate the aberrant glucose metabolism may also play an important role in radioresistance of DIPG and other pHGGs under the influence of TP53 mutation.

Acquired radioresistance induced by radiotherapy $\mathrm{Al}$ though radiotherapy is used to eradicate any remnant tumor cells after surgery, radiation is ironically known to transform tumor cells into a more aggressive and radioresistant form, for which the treatment options are very limited [42]. Several mechanisms have been proposed for this paradoxical phenomenon. Firstly, radiotherapy-induced reoxygenation can stabilize HIF-1 signaling and this is believed to be involved in radioresistance. Radiation is delivered in multiple dose fractions to enable tumor reoxygenation in-between fractions [43]. Tumor shrinkage over the course of radiotherapy allows blood vessels to reach previously distant cells, thus reducing the hypoxic fraction and reoxygenating hypoxic cells. Following delivery of radiotherapy, reoxygenation and a temporary reduction in hypoxia occurs due to the aerobic tumor cells being killed. However, the radiotherapy-induced reoxygenation also elevates the production of ROS, induces depolymerization of cytoplasmic stress granules containing HIF-1-regulated mRNA transcripts, and activates PI3K/ AKT/mTOR pathway, all of which eventually stabilizes the HIF-1 expression in surviving tumor cells [44]. Secondly, the post-radiotherapy upregulation of genes controlling DNA repair, cell proliferation and anti-apoptosis is also believed to play an important role in radiotherapy-induced radioresistance, particularly when a sub-lethal dose of radiotherapy was cumulatively delivered [45]. This has been frequently reported by studies investigating adult glioblastomas and a very recent report has also confirmed the similar findings in pHGGs [46]. Last but not least, radiotherapy-induced generation and enrichment of cancer stem cells is also a major obstacle for maintaining the efficacy of radiotherapy to eradicate cancer cells. Bao et al. reported for the first time that the percentage of CD133-positive cells increased in gliomas after radiotherapy, indicative of an important role of radiotherapy itself in the development of radioresistance [47]. In addition, recent studies have consistently reported that radiotherapy enhances the transdifferentiation of glioma stem-like cells into tumor derived endothelial cells which may further contribute to neovasculature and radioresistance $[48,49]$. In the end, the surviving radioresistant tumor cells will eventually proliferate and lead to cancer relapse within the previously irradiated field, which challenges the role of reirradiation in the treatment of recurrent HGGs.

\section{Role of hypoxia and circadian rhythm in radioresistance of HGGs}

Circadian rhythms are endogenous, 24-h cycles that regulate physiological, behavioral and cellular changes in organisms. These rhythms control pathological processes 
that contribute to HGGs, including those involving cell cycle, immune surveillance, metabolism and more [50, 51]. Radiotherapy induced DNA damage has also been shown to be regulated by circadian rhythms [52]. Furthermore, GSCs depend on circadian rhythms for growth, metabolism and stemness [11], all of which impact the efficacy of radiotherapy. A limited number of studies have shown that HIF pathways interact with the circadian pathways though this is yet to be investigated in HGG radiotherapy models.

The biology of circadian rhythms and the molecular clock The circadian machinery is disrupted in a wide range of cancers [53], including HGGs [11, 54-56], and it appears to have context-dependent roles that contribute to malignant behavior and radiotherapy resistance. Circadian rhythms are generated by a molecular clock encoded in the genome, which consists of a network of interlocking transcriptional-translational feedback loops (Fig. 3a). The central feedback loop is composed of transcription factors, BMAL1 and CLOCK, which dimerize and bind to the E-box DNA sequence in the promoters of clock-controlled genes, including the period (PER) and cryptochrome (CRY) genes. CLOCK/BMAL1 induces the expression of PER and CRY isoforms, which act as negative regulators of CLOCK/BMAL1 activity. PER and CRY proteins accumulate, before being degraded by the proteasome through pathways including the casein kinases. This enables CLOCK/BMAL1 activity to resume, repeating the cycle approximately every $24 \mathrm{~h}$. There are also additional feedback loops involving ROR $\alpha$ and REV-ERBs, which act to increase or repress the expression of BMAL1, respectively [50]. Circadian rhythms are maintained in nearly every cell of the body and they are cell autonomous, but individual cells are synchronized to one another by external cues, such as light, food intake and temperature. Epidemiological studies have shown that environmental disruption of circadian rhythms may increase the risk of developing some cancers [57-59]. Genetic disruption of circadian clocks in animals can also promote tumorigenesis and progression of specific cancers [52, 60-62].

Studies on circadian rhythms and gliomas There are limited studies on circadian rhythms specifically in HGGs. Abnormal rhythms are associated with highgrade brain tumors $[54,63]$ and HGGs may have different cellular circadian rhythms when compared to surrounding healthy tissues $[55,56]$. These altered rhythms can result from genetic variations, chromosomal amplifications and/or changes to gene expression in clockrelated genes. For example, a genetic variant of PER1 has been associated with overall glioma risk [64], and decreased PER1 mRNA and protein has been observed in HGGs when compared to lower-grade gliomas (LGG) [65]. REV-ERB $\beta$ (NR1D2) is highly expressed in glioblastoma, and is required for cell proliferation, migration and invasion [66]. Expression of CRY1 and CRY2 is lower in HGGs compared to surrounding non-glioma cells [67]. Chronic jetlag, an environmental circadian disruption, leads to differential regulation of glioma-related genes in the brain of mice with and without a functioning clock. These results indicate that the molecular clock could potentially play a role in glioma risk [68].

The CLOCK gene is amplified in $~ 5-9 \%$ of glioblastoma patients $[69,70]$. In support of this, several studies have found that CLOCK expression is increased in HGGs when compared to LGG or non-malignant cells [54, 71]. CLOCK and its binding partner, BMAL1, are thought to contribute to glioma proliferation, migration,

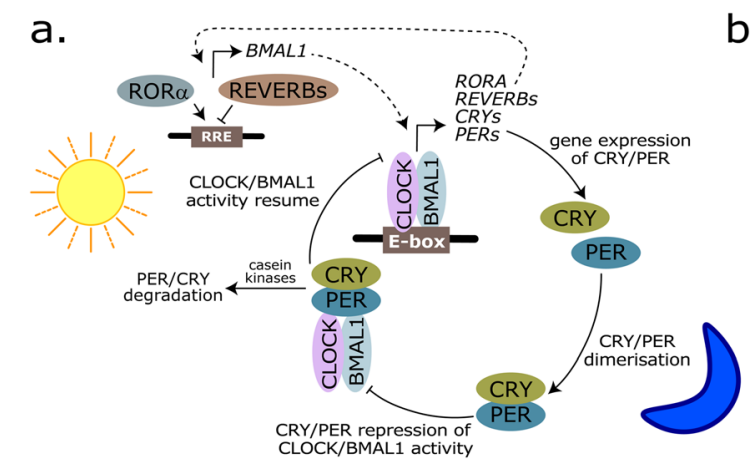

\section{b. 24 Hour Pattern of Circadian Gene/Protein Expression}

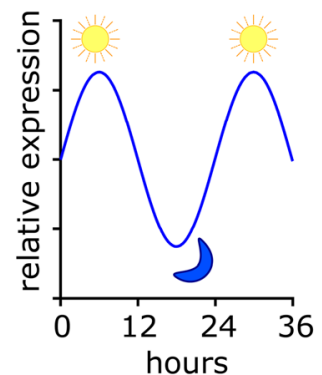

Fig. 3 a The basic mammalian circadian clock loop consists of transcription factors BMAL1 and CLOCK which express PER (PER1, PER2, PER3), CRY (CRY1, CRY2), REV-ERB (NR1D1, NR1D2) and ROR (RORA, RORB, RORC) genes. The PER and CRY proteins accumulate and repress BMAL1/CLOCK activity before being degraded through a mechanism involving casein kinases and the proteasome, which allows BMAL1 and CLOCK activity to resume. In a second loop, the expressed ROR and REV-ERB proteins act to enhance or repress expression of BMAL1 gene. Genes/mRNAs indicated in italics, proteins indicated by colored ovals. b Circadian genes demonstrate cyclical expression over a $24 \mathrm{~h}$ period. BMAL1, brain and muscle aryl hydrocarbon receptor nuclear translocator (ARNT)-like 1; CLOCK, circadian locomotor output cycles kaput; PER, period; ROR, RAR-related orphan receptor 
stemness and metabolic reprogramming $[11,66,70,71]$ and a recent paper proposed that GSCs use BMAL1 and CLOCK to alter these characteristics and gain a physiological advantage [11]. CLOCK and BMAL1 knockdown decreased glioblastoma proliferation through cell-cycle arrest and apoptosis. This effect was especially potent in GSCs when compared to differentiated glioblastoma cells. Normal neural stem cell growth was unaffected by CLOCK and BMAL1 knockdown, indicating that glioblastoma cells are unique in relying on these circadian transcription factors for maximum cell growth [11].

Taken together, these studies support the emerging idea that BMAL1 and CLOCK have tumor promoting qualities in HGGs, while PER (and possibly CRY) may have tumor suppressing roles, though this is likely to be context and cancer dependent. A pan-cancer study using genomic, transcriptomic and clinical data largely supports this [55]. Downregulation of the circadian genes encoding CRY2, PER1, PER2, PER3, CLOCK, REVERB $\beta$, ROR- $\alpha$ and ROR- $\beta$ was associated with significantly higher mortality rates in the glioma cohort, hinting at possible tumor suppressor roles. Overexpression of BMAL1 in gliomas led to a poorer survival outcome [55], indicating a potential tumor promoting role. Interestingly, in this study, CLOCK downregulation in gliomas was associated with higher mortality [55] which conflicts with other studies where CLOCK is overexpressed [54] or amplified [69, 70] in HGGs and contributes to malignant changes [11]. However, this study was limited by a small number of non-tumor brain samples (five), which were used as a comparison to determine over- and under-expression [55]. Further study is clearly warranted but overall circadian changes were strongly linked to gliomas [55].

Links between circadian disruption, tumor hypoxia and HIF One interesting finding to emerge from this largescale multi-cancer bioinformatics analysis was an association between markers of tumor hypoxia and circadian dysregulation, particularly in gliomas [55]. The loss of proposed circadian tumor suppressors and/or an increase in circadian tumor promoters was associated with markers of tumor hypoxia, leading the authors to propose that circadian dysregulation is exacerbated by hypoxia [55]. There is evidence that hypoxia and HIF can alter circadian rhythms and vice versa in a nontumor context [72-75]. This bidirectional relationship may be important in HGGs, as both hypoxia and circadian disruption can play a role in tumor progression. While these relationships have only been studied in specific cell types and under certain circumstances, these studies provide justification for exploring in the context of HGGs.
Circadian gene expression is altered by hypoxia in hepatocellular carcinoma cells through a mechanism dependent on HIF-1 $\alpha$ [76]. PER1 and CLOCK levels increase in the brain when mice are exposed to hypoxia [77]. These observations have led to several proposed mechanisms, some of which have evidence in vitro and in vivo. Hypoxia and HIF- $1 \alpha$ can directly alter and regulate the molecular clock through HIF-1 $\alpha$ binding to BMAL1 to express E-box circadian genes, including the PER and CRY genes in vitro [78]. Overexpression and stabilization of HIF-1 $\alpha$ increases expression levels of circadian genes $[73,75]$. This may mean that hypoxia could lead to the expression of circadian genes at inappropriate times. HIF- $1 \alpha$ can also alter the molecular clock through indirect effects. HIF controls genes involved in the production of acid, and an acidic environment suppresses oscillation of the molecular clock by inhibiting mTORC1 [79].

Circadian rhythmicity also can affect the HIF-1 $\alpha$ hypoxic response. HIF-1 activity is gated by the circadian clock, meaning that the strength of the hypoxic response is clock-regulated [73]. Furthermore, there is an E-box in the promoter of the $H I F 1 A$ gene, indicating that CLOCK/BMAL1 can induce expression of HIF1A [73]. CRY1 can bind directly to the HIF- $1 \alpha$ protein in mice, which dampens HIF-1 expression of target genes [80]. This means that during periods of high CRY1 expression, the maximal HIF- $1 \alpha$ hypoxic response can be dampened, though still present. During periods of low CRY1, HIF activity increases, which leads to cellular proliferation and migration in some circumstances [80]. Furthermore, PER2 has been found to bind to HIF- $1 \alpha$, which increases HIF-1 activity, and has the opposite effect of CRY2 [81].

Synergistic effects have also been observed between HIF and CLOCK/BMAL1. Both heterodimer transcription factors co-occupy core clock genes, including PER1 and PER2, and it is thought that this is due to both Ebox and hypoxia response element (HRE) motifs being present in the promoter of the same gene [73]. The consequences of these findings for HGGs is difficult to interpret, as most of these studies were conducted in tissues other than the brain and not in gliomas. However, circadian rhythms, hypoxia and HIF-1 have all been shown to contribute to enhance progression in HGGs and should be investigated further.

Circadian rhythms and radiotherapy DNA repair genes have cyclical expression patterns in mRNA and protein expression $[82,83]$ and there is some initial evidence that these rhythms can influence radiosensitivity. Radioresistance is highest in the second half of the daily light span when mice are exposed to whole body irradiation [84]. When the same mice were exposed to a jet- 
lag protocol 'shifting their time of day', radiation sickness was worsened. Further studies have begun to unravel some of the possible reasons for circadianregulated radiosensitivity. Nucleotide excision repair by xeroderma pigmentosum, a DNA damage recognition protein, peaks in the afternoon/evening and is at its lowest in the night/early morning in the mouse brain cortex [85] and the skin [86]. These effects can be seen in glioma models, as rat glioma cells synchronize at the G2/ $\mathrm{M}$ transition of the cell cycle during periods of high PER2 expression, and this makes them more sensitive to radiotherapy $[87,88]$. PER1, another period isoform, may have a role in radiation-induced apoptosis and DNA damage in gliomas, as downregulation of PER1 attenuated DNA damage in U343 glioma cells [89]. This may have consequences for glioma treatment as decreased levels of PER1 have been observed in HGGs [65] and this may make tumor cells less susceptible to apoptosis and other damaging effects from ionizing radiation [89].

The response to radiation in the tissues surrounding tumors also follow daily circadian rhythms [52] and it might be possible to minimize side effects by administering radiotherapy to HGGs during a time of day when healthy tissues are less susceptible to its effects (chronoradiotherapy). Environmentally disrupted circadian rhythms in mice, brought on by a shifting light cycle, alters the gut bacterial composition and host radiosensitivity through an unexplained mechanism [90]. One study in breast cancer suggested that radiotherapy had more toxicity and side effects in the morning, and this was associated with a genetic variant of PER3 [91]. Time of treatment administration affected the response to radiation in females with bone metastases but had no effect in males, indicating that gender differences and sex hormones should be investigated for a role in circadian regulation of the response to radiotherapy [92]. A similar effect was seen in patients treated with whole brain radiotherapy for metastases. The time of day for whole brain radiotherapy was significantly related to overall survival in elderly females, while there was no apparent relationship in males [93]. Other clinical studies have shown that radiotherapy timing affects treatment response and toxicity depending on the tissue of interest [94-100], though some of them clearly had confounding factors. When these factors were accounted for, differences disappeared. For example, in one study, they found that patients with more severe signs of illness and metastases tended to be given afternoon appointments [96]. When this was accounted for, differences between groups disappeared.

Studies thus far on radiotherapy and circadian rhythms are limited by several factors. The studies conducted thus far are not directly comparable as the endpoints of individual trials are not the same. Some studies used overall survival as the endpoint, thus assessing circadian timing effects on tumor itself, while other studies used side effects as the endpoint, which generally reflects the effects of radiation on the surrounding healthy tissues. Healthy tissues may not have the same circadian oscillation as tumor tissues, and timing for maximal tumor response or for minimal healthy tissue damage therefore may not be the same, making it difficult to compare a small number of studies. Furthermore, there is no clear definition of morning, afternoon and evening, and the times used in different studies were not the same. No studies to our knowledge have focused on HGGs, and how hypoxia and circadian rhythms may interact to affect radiosensitivity of the tumor. Further prospective randomised control trials are required to determine if radiotherapy can be timed to target cancer cells and avoid toxicity in healthy tissues.

Circadian rhythms, metabolism and epigenetics The circadian clock has strong links to metabolism, and cancer cells, including those in gliomas, have significantly altered metabolism that contributes to radioresistance. Specific diets and timed feedings can alter the circadian clock in various organs [101-106] and metabolites in human blood and muscle show rhythmic circadian patterns $[107,108]$, indicating there is a bidirectional relationship between circadian rhythms and metabolism. Animal models of jet lag and shift work can alter circadian rhythms, leading to increased rates of cancer and for some cancers this may be driven by metabolic changes linked to circadian disruption $[109,110]$. The circadian clock also affects cellular metabolism and glioma cells are known to have abnormal metabolism.

Oncogenic changes in glioblastoma, including mutations in TP53, amplification of MYC or deletion of PTEN, alter metabolism and increase glycolysis [111, 112]. The expression of genes for MYC, PTEN and p53 are known to cycle in a circadian rhythmic fashion [83, 113] and there may be crosstalk between glioma cell metabolism and circadian rhythms. For example, in osteosarcoma and neuroblastoma cells, MYC disrupts the circadian clock by activating CLOCK and BMAL1, which alters glucose metabolism and glutaminolysis [114]. MYC has been shown to drive an abnormal metabolic program in glioblastoma cells and inhibition of this pathway shows therapeutic benefit in animal models [112]. Circadian rhythms can also act on the MYC pathway, as CRY2 promotes MYC degradation, and a loss of CRY2 stabilizes MYC, enhancing cellular transformation [115].

Additional HGG oncogenic pathways that control metabolism have been shown to interact bidirectionally with circadian rhythms. AKT and mTOR can set the pace for the circadian clock [116], and mTOR itself is cyclically ubiquitylated according to the clock [117]. 
While most of these findings have come from healthy humans/animals or cancers other than HGGs, one study found that GSCs can reprogram their metabolism to promote growth and survival and that this occurs through a mechanism using the circadian clock and epigenetic changes [11]. In GSCs, BMAL1 preferentially binds to the promoter region of a significant number of metabolism genes, particularly those involved in glycolysis and the TCA cycle. In normal neural stem cells, BMAL1 only bound to half of these genes. This indicates that BMAL1, a key circadian rhythm regulator, may be capable of inducing the expression of a significant number of metabolic genes specifically in GSCs [11]. The preferential binding was due to epigenetic histone modifications which enabled greater access to E-box binding sites in GSCs [11]. This study clearly demonstrates that circadian rhythms can be used by HGGs to alter metabolism, including glycolysis which supports HGG progression.

\section{Targeting HIF-1, glucose metabolism and circadian rhythms as an approach to improving radiosensitivity of HGGs HIF-1}

Theoretically, the deregulated glucose metabolism of tumor cells can be targeted at different levels, either by targeting the upstream transcriptional factor HIF-1 or via inhibiting key enzymes involved in downstream glucose metabolic pathways. HIF-1 inhibition leads to metabolic changes, with a decreased rate of glycolysis [118] and increased rate of tricarboxylic acid cycle [119]. Because the production of ROS are accompanied by enhanced mitochondrial oxidation, the therapeutic strategy of HIF-1 inhibition could potentially enhance the effect of radiotherapy [120], due to sharing the same mechanisms of cell killing. On the other hand, many other drugs targeting different signaling pathways may also be attributed partly to their secondary effect of HIF-1 inhibition. For example, anti-mitochondrial agents that reduce oxygen consumption spare more oxygen within tumor cells, leading to alleviated hypoxia and lower levels of HIF-1 [121]. Drugs targeting PI3K/Akt pathway also repress HIF-1 activation and sensitize tumor cells to apoptosis [122]. Although a large number of novel compounds have been shown to inhibit HIF-1 in preclinical setting, to the best of our knowledge there is no compound in clinical trials that directly and specifically inhibits HIF-1 activity. The molecular targeting of HIF-1 activity is very challenging because the pathways are complex, and it remains unclear where the main vulnerabilities lie.

As an alternative approach, hypoxia-activated prodrugs (HAPs) have been developed to specifically target hypoxic cells of tumors [123]. HAPs can be metabolized under hypoxic conditions to release an active drug that is more cytotoxic to hypoxic cells than normoxic cells through mechanism of bioreduction [124]. Therefore, the combination of radiotherapy and bioreductive drugs presents an attractive opportunity for synergistic effects. Nitro-based HAPs were the first generation of bioreductive drugs that undergo the oxygen-sensitive redox cycling [125]. This class of HAPs mimics oxygen to radiosensitize tumor cells [126]. Despite promising results from pre-clinical models, outcome of clinical trials were disappointing, with combination arm showing no significant survival benefit compared to radiotherapy alone in HGG patients [127]. The failure was thought to be due to the low drug concentrations achieved being not enough for radiosensitization [128]. Further attempts have been made to develop the second generation of HAPs including pimonidazole, etanidazole, and nimorazole. Due to the long half-lives of these drugs there was greater toxicity in human studies, and both pimonadazole and etanidazole showed negative results in phase I clinical trials [129], with nimorazole being the only one showing no major adverse effects in combination with radiotherapy [130]. It is now being routinely used in combination with conventional radiotherapy to treat head and neck cancers in Denmark [131] and being further evaluated in Phase II trials for the treatment of head and neck cancers in combination with hyperfractionated radiotherapy (NCT01880359, NCT01950689). Following the initial interest in oxygen mimetic bioreductive drugs, a new generation of DNA-targeting bioreductive prodrugs have been developed to be activated to cytotoxic drugs in the hypoxic environment, with PR-104 and TH302 (evofosafamide) being the two representative drugs in this class. A recent preclinical study in breast cancer tumor xenografts indicated that both PR-104 and TH302 sensitized tumors to irradiation, particularly in BRCA2-knockout mutants [132]. Although there are no clinical trials testing the two drugs in combination with radiotherapy, $\mathrm{TH}-302$ has been reported to be safe in combination with VEGF inhibitor bevacizumab in patients with recurrent glioblastoma [133]. Tirapazamine (TPZ) is one of the best characterized HAPs that has been tested in various preclinical and early phase clinical trials and has yielded promising results. Preclinically, TPZ has showed synergistic or enhanced efficacy in combination with radiotherapy to treat melanoma cell lines and mouse models [134], which led to a phase 1 trial of TPZ and radiotherapy in the treatment of refractory solid tumors, suggesting TPZ can be safely used concurrently with radiotherapy as a radiosensitizer [135]. However, the combination of TPZ and chemoradiotherapy failed in a phase III trial for the treatment of head and neck cancers, although the hypoxic tumors were not selected upfront [131]. Moreover, the combination of TPZ and radiotherapy also failed to show benefit in a single-arm, openlabelled phase II study for glioblastoma. There was 
acceptable toxicity but no significant improvement in survival [136]. The repeated failings of trials testing these bioreductive prodrugs that have shown promising results preclinically raise questions as to which factors are limiting clinical success. Perhaps the most important limitation of bioreductive prodrugs in the context of these clinical trials is the failure to identify patients who are most likely to benefit from HAPs. Regarding the treatment of HGGs, penetration of the blood brain barrier is another critical factor that should be assessed comprehensively in both preclinical and clinical models.

\section{Glucose metabolism}

There are several key glycolytic enzymes that can be targeted pharmacologically in cancer treatment. The first orally administered small molecule that was tested in the early 1980's to inhibit glycolysis was lonidamine, as an inhibitor of mitochondria-bounded hexokinase [137]. Lonidamine was later tested in a randomized clinical trial for glioblastoma in combination with radiotherapy, but failed to show therapeutic improvement compared to radiotherapy alone [138]. Following the failure of lonidamine, a structural analogue of glucose, 2-deoxy-D-glucose, was tested. Metabolically, it inhibits glycolysis via competitive inhibition of hexokinase 2 that controls the first rate-limiting step of glycolysis [139-141]. It was also reported to reduce the endoplasmic reticulum stressrelated pathways which is significantly correlated to the radioresistance of GSCs [142]. Furthermore, 2-deoxy-Dglucose is also able to modify the DNA repair pathways to optimize radiotherapy in HGG treatment [143]. Treatment with 2-deoxy-D-glucose is cytostatic and radiosensitizes a range of cancer cells including HGGs [144]. These findings led to a phase I/II trials testing 2deoxy-D-glucose in combination with radiotherapy in patients with HGG, which demonstrated this combined treatment was well tolerated without any acute toxicity or late radiation damage to the normal brain tissue [145]. This combination therapy also resulted in a moderate increase in median survival with a significantly improved quality of life [146]. Another leading compound 3-bromopyruvate, a pyruvate analogue, is both an alkylating agent and an inhibitor of hexokinase 2. 3bromopyruvate inhibits tumor growth in a dosedependent manner in vivo [147], but its off-target effect as well as the inability to penetrate the blood brain barrier impeded its further application in HGGs [148]. Another key enzyme that can be pharmacologically targeted is pyruvate dehydrogenase kinase, which controls the rate and amount of pyruvate entering the tricarboxylic acid cycle by negatively regulating pyruvate dehydrogenase activity. Inhibition of pyruvate dehydrogenase kinase shifts the glucose metabolism and increases oxygen consumption of tumor cells, which in turn inducing higher level of ROS, thus improving the radiosensitivity of the tumor cells [149]. Dichloroacetate (DCA), a small molecule inhibitor of pyruvate dehydrogenase kinase (PDK) with the potential for such metabolic modulation, has been shown to reverse the Warburg effect, thereby inhibiting both tumor cell growth and angiogenesis [150, 151]. By combining with radiotherapy, dichloroacetate enhances the radiosensitivity of several types of cancer in vitro [152-154] and in vivo including adult and pediatric HGGs $[155,156]$. Dichloroacetate has been used as an orphan drug for various acquired and congenital disorders of mitochondrial metabolism in both adult and pediatric patients for decades and has recently been demonstrated to be feasible and well-tolerated in patients with recurrent HGGs in a recent Phase I clinical trial [157]. In addition, a recent study has tested the efficacy of DCA in a small cohort of HGG patients, suggesting metabolic modulation through pyruvate dehydrogenase kinase inhibition as a novel therapeutic strategy for the treatment of this devastating brain tumor [158]. Interestingly, the human toxicity from chronic DCA exposure is generally limited to a reversible peripheral neuropathy that is now known to be influenced by age. The dose-limiting neuropathy in the glioblastoma study above occurred at a DCA dose that is known to cause no side effects in children. The identical dose known to cause neuropathy in adults with mitochondrial disease has been safely given to children with congenital mitochondrial diseases for many years [159]. These findings and clinical results suggest that trials targeting the pediatric brain tumor population with DCA may be warranted, particularly given the safety and reduced toxicity of chronic administration of DCA in children. Moreover, melatonin, the secretory product of pineal gland, has also been recently reported to promote the synthesis of acetyl-CoA from pyruvate by inhibiting PDK in breast cancer models [160]. The inhibitory effect of melatonin on PDK not only reverses the Warburg effect, reduces tumor mass, and improves the sensitivity of tumor cells to chemoradiotherapy [160, 161], it also leads to a circadian rhythm of glucose metabolism in these cancer cells $[162,163]$.

\section{Circadian clock}

Because components of the molecular clock sustain growth, metabolism and stemness in HGGs [11], there may be opportunities to identify new drug targets and even combine with radiotherapy. Sulli et al., identified two REV-ERB agonists, SR9009 and SR9011, that impair glioblastoma growth in vivo and improve survival without causing toxicity [164]. REV-ERBs repress the transcription of BMAL1, so REV-ERB agonists should ultimately decrease BMAL1 levels. This would support the finding that BMAL1 drives growth and progression 
in glioblastoma [11]. The efficacy of SR9009 in a glioblastoma mouse model was similar to that of temozolomide, the current therapeutic standard for this cancer [164]. There are a number of other recently discovered compounds that target circadian proteins and some of these have been shown to have anti-cancer effects. Further work will be required to determine if this may be a useful strategy for inhibiting growth and improving the radiosensitivity of HGGs. On the other hand, future research has also been suggested to focus on chronoradiotherapy, where radiotherapy is given at specific timesof-the-day when a tumor is likely to be most susceptible to its effects and surrounding healthy tissues are the least susceptible [165]. Chronoradiotherapy may offer a promising new way to improve outcomes of cancer treatment as well as alleviating side-effects, though wellcontrolled studies are still needed to determine if there is a benefit. There are few prospective randomized control trials on chronoradiotherapy and only one study that has identified the genetic association between the time-of-day differences and radiotherapy outcomes [91]. Further work is also needed to identify a potential biomarker underlying this effect to predict which patients might benefit the most from chronoradiotherapy.

\section{Conclusions}

HGGs are fast-growing, aggressive tumors with few treatment options. Radiotherapy is a first-line treatment option, though radioresistance commonly develops in HGGs and this is at least partially due to hypoxia and activation of the HIF pathway. HIF is also known to regulate the expression of genes involved in glycolysis and maintaining stemness of HGGs. Recent work has uncovered links between the circadian clock and HIF

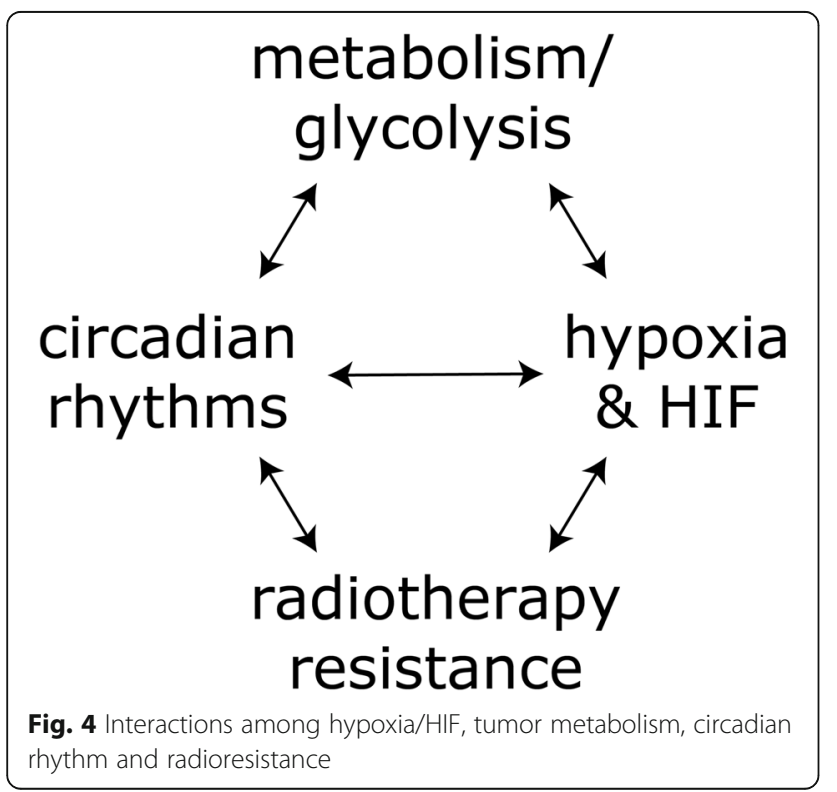

pathway while the circadian pathway has been found to drive proliferation, survival and stemness in GSCs [11, 70] (Fig. 4). Although there are a large number of studies focusing on all these abovementioned aspects, little is known about how HIF and circadian rhythms may interact on a mechanistic level, and how this interaction further modulates tumor metabolism and contributes to radioresistance in HGGs. The relationship between tumor metabolism, circadian rhythms and HIF is complex and future studies should focus on how these key pathways interact to affect the radiosensitivity of HGGs so that clinical outcomes can be further improved.

\section{Abbreviations}

ADP: Adenosine diphosphate; ATP: Adenosine triphosphate; CA IX: Carbonic anhydrase 9; DCA: Dichloroacetate; DIPG: Diffuse intrinsic pontine glioma; G6-P: Glucose-6-phosphate; G6PD: Glucose-6-phosphate dehydrogenase;

GLUT: Glucose transporters; GSC: Glioma stem cell; GSH: Glutathione; GSSG: Glutathione disulfide; HAP: Hypoxia-activated prodrug; HGG: Highgrade glioma; HIF-1: Hypoxia-inducible factor; HK: Hexokinase; LDHA: Lactate dehydrogenase A; LGG: Low-grade glioma; MCT4: Monocarboxylate transporter 4; NHE1: Na+/H+ exchanger isoform 1; PDH: Pyruvate dehydrogenase; PDK: Pyruvate dehydrogenase kinase; PHGG: Paediatric highgrade glioma; PPP: Pentose Phosphate Pathway; ROS: Reactive oxygen species; TIGAR: TP53-induced glycolysis and apoptosis regulator;

TPZ: Tirapazamine; VEGF: Vascular endothelial growth factor

\section{Acknowledgements}

The authors acknowledge funding support from NHMRC, Cure Brain Cancer Foundation, The DIPG Collaborative, The Cure Starts Now, The Mark Hughes Foundation, Charlie Teo Foundation, NSW Health, Sydney West Radiation Oncology Network.

\section{Authors' contributions}

The manuscript was conceived by HS, KC, HG, EH. The manuscript and figures were prepared by HS and KC. Further edits and revision were made by $\mathrm{HG}$ and $\mathrm{EH}$. The authors read and approved the final manuscript.

Availability of data and materials

Not applicable.

Ethics approval and consent to participate

Not applicable.

Consent for publication

Not applicable.

\section{Competing interests}

Not applicable. The authors have declared that no conflict of interest exists.

\section{Author details}

${ }^{1}$ Translational Radiation Biology and Oncology Laboratory, Centre for Cancer Research, Westmead Institute for Medical Research, Westmead, New South Wales 2145, Australia. ${ }^{2}$ Sydney Medical School, University of Sydney,

Camperdown, New South Wales, Australia. ${ }^{3}$ Faculty of Medicine and Health \& Charles Perkins Centre, University of Sydney, Camperdown, New South Wales, Australia. ${ }^{4}$ Department of Radiation Oncology, Crown Princess Mary Cancer Centre, Westmead Hospital, Westmead, New South Wales, Australia. ${ }^{5}$ Blacktown Hematology and Cancer Centre, Blacktown Hospital, Blacktown, New South Wales, Australia.

Received: 18 June 2020 Accepted: 1 July 2020

Published online: 07 July 2020

References

1. Stupp R, Mason WP, van den Bent MJ, Weller M, Fisher B, Taphoorn MJ, et al. Radiotherapy plus concomitant and adjuvant temozolomide for glioblastoma. N Engl J Med. 2005;352(10):987-96. 
2. Hegi ME, Diserens AC, Gorlia T, Hamou MF, de Tribolet N, Weller M, et al. MGMT gene silencing and benefit from temozolomide in glioblastoma. N Engl J Med. 2005;352(10):997-1003.

3. Warren KE. Diffuse intrinsic pontine glioma: poised for progress. Front Oncol. 2012;2:205.

4. Quintiliani M. The oxygen effect in radiation inactivation of DNA and enzymes. Int J Radiat Biol Relat Stud Phys Chem Med. 1986;50(4):573-94.

5. Rockwell S, Dobrucki IT, Kim EY, Marrison ST, Vu VT. Hypoxia and radiation therapy: past history, ongoing research, and future promise. Curr Mol Med. 2009;9(4):442-58

6. Bartrons R, Caro J. Hypoxia, glucose metabolism and the Warburg's effect. J Bioenerg Biomembr. 2007;39(3):223-9.

7. Pugh CW, Ratcliffe PJ. Regulation of angiogenesis by hypoxia: role of the HIF system. Nat Med. 2003;9(6):677-84.

8. Gatenby RA, Smallbone K, Maini PK, Rose F, Averill J, Nagle RB, et al. Cellular adaptations to hypoxia and acidosis during somatic evolution of breast cancer. Br J Cancer. 2007:97(5):646-53.

9. Akakura N, Kobayashi M, Horiuchi I, Suzuki A, Wang J, Chen J, et al. Constitutive expression of hypoxia-inducible factor-1alpha renders pancreatic cancer cells resistant to apoptosis induced by hypoxia and nutrient deprivation. Cancer Res. 2001;61(17):6548-54.

10. Moeller BJ, Dewhirst MW. HIF-1 and tumour radiosensitivity. Br J Cancer. 2006;95(1):1-5.

11. Dong Z, Zhang G, Qu M, Gimple RC, Wu Q, Qiu Z, et al. Targeting glioblastoma stem cells through disruption of the circadian clock. Cancer Discov. 2019;9(11):1556-73.

12. Kim W, Lee S, Seo D, Kim D, Kim K, Kim E, et al. Cellular stress responses in radiotherapy. Cells. 2019;8(9):1105

13. Hambardzumyan D, Squatrito M, Holland EC. Radiation resistance and stemlike cells in brain tumors. Cancer Cell. 2006;10(6):454-6.

14. Schulz A, Meyer F, Dubrovska A, Borgmann K. Cancer stem cells and Radioresistance: DNA repair and beyond. Cancers (Basel). 2019;11(6):862.

15. Schaue $\mathrm{D}, \mathrm{McBride} \mathrm{WH}$. Counteracting tumor radioresistance by targeting DNA repair. Mol Cancer Ther. 2005;4(10):1548-50.

16. Tang L, Wei F, Wu Y, He Y, Shi L, Xiong F, et al. Role of metabolism in cancer cell radioresistance and radiosensitization methods. J Exp Clin Cancer Res. 2018;37(1):87

17. Hockel M, Vaupel P. Tumor hypoxia: definitions and current clinical, biologic, and molecular aspects. J Natl Cancer Inst. 2001;93(4):266-76.

18. Muz B, de la Puente P, Azab F, Azab AK. The role of hypoxia in cancer progression, angiogenesis, metastasis, and resistance to therapy. Hypoxia (Auckl). 2015:3:83-92

19. Evans SM, Judy KD, Dunphy I, Jenkins WT, Nelson PT, Collins R, et al. Comparative measurements of hypoxia in human brain tumors using needle electrodes and EF5 binding. Cancer Res. 2004;64(5):1886-92.

20. Mendichovszky I, Jackson A. Imaging hypoxia in gliomas. Br J Radiol. 2011; 84 Spec No 2:S145-58

21. Proescholdt MA, Merrill MJ, Stoerr EM, Lohmeier A, Pohl F, Brawanski A. Function of carbonic anhydrase IX in glioblastoma multiforme. NeuroOncology. 2012;14(11):1357-66.

22. Kalpathy-Cramer J, Gerstner ER, Emblem KE, Andronesi O, Rosen B. Advanced magnetic resonance imaging of the physical processes in human glioblastoma. Cancer Res. 2014;74(17):4622-37.

23. Leon SP, Folkerth RD, Black PM. Microvessel density is a prognostic indicator for patients with astroglial brain tumors. Cancer. 1996;77(2):362-72.

24. Erpolat OP, Gocun PU, Akmansu M, Ozgun G, Akyol G. Hypoxia-related molecules HIF-1alpha, CA9, and osteopontin : predictors of survival in patients with high-grade glioma. Strahlenther Onkol. 2013;189(2):147-54.

25. Blandin AF, Durand A, Litzler M, Tripp A, Guerin E, Ruhland E, et al. Hypoxic environment and paired hierarchical 3D and 2D models of pediatric H3.3mutated gliomas recreate the patient tumor complexity. Cancers (Basel). 2019;11(12):1875.

26. Yeom KW, Lober RM, Nelson MD Jr, Panigrahy A, Bluml S. Citrate concentrations increase with hypoperfusion in pediatric diffuse intrinsic pontine glioma. J Neurooncol. 2015;122(2):383-9.

27. Hu CJ, Wang LY, Chodosh LA, Keith B, Simon MC. Differential roles of hypoxia-inducible factor 1alpha (HIF-1alpha) and HIF-2alpha in hypoxic gene regulation. Mol Cell Biol. 2003;23(24):9361-74.

28. Eales KL, Hollinshead KE, Tennant DA. Hypoxia and metabolic adaptation of cancer cells. Oncogenesis. 2016;5:e190.
29. Seagroves TN, Ryan HE, Lu H, Wouters BG, Knapp M, Thibault P, et al. Transcription factor HIF-1 is a necessary mediator of the pasteur effect in mammalian cells. Mol Cell Biol. 2001;21(10):3436-44.

30. Warburg O. On the origin of cancer cells. Science. 1956;123(3191):309-14.

31. Liberti MV, Locasale JW. The Warburg effect: how does it benefit cancer cells? Trends Biochem Sci. 2016:41(3):211-8.

32. Semenza GL. HIF-1 and tumor progression: pathophysiology and therapeutics. Trends Mol Med. 2002;8(4 Suppl):S62-7.

33. Zhou Y, Zhou Y, Shingu T, Feng L, Chen Z, Ogasawara M, et al. Metabolic alterations in highly tumorigenic glioblastoma cells: preference for hypoxia and high dependency on glycolysis. J Biol Chem. 2011;286(37):32843-53.

34. Sattler UG, Meyer SS, Quennet V, Hoerner C, Knoerzer H, Fabian C, et al. Glycolytic metabolism and tumour response to fractionated irradiation. Radiother Oncol. 2010;94(1):102-9.

35. Pitroda SP, Wakim BT, Sood RF, Beveridge MG, Beckett MA, MacDermed DM, et al. STAT1-dependent expression of energy metabolic pathways links tumour growth and radioresistance to the Warburg effect. BMC Med. 2009; 7:68.

36. Wanka C, Steinbach JP, Rieger J. Tp53-induced glycolysis and apoptosis regulator (TIGAR) protects glioma cells from starvation-induced cell death by up-regulating respiration and improving cellular redox homeostasis. J Biol Chem. 2012;287(40):33436-46.

37. Pena-Rico MA, Calvo-Vidal MN, Villalonga-Planells R, Martinez-Soler F, Gimenez-Bonafe P, Navarro-Sabate A, et al. TP53 induced glycolysis and apoptosis regulator (TIGAR) knockdown results in radiosensitization of glioma cells. Radiother Oncol. 2011;101(1):132-9.

38. Werbrouck C, Evangelista CCS, Lobon-Iglesias MJ, Barret E, Le Teuff G, Merlevede J, et al. TP53 pathway alterations drive Radioresistance in diffuse intrinsic pontine gliomas (DIPG). Clin Cancer Res. 2019;25(22):6788-800.

39. Feng $Z$, Zhang $H$, Levine $A J$, Jin $S$. The coordinate regulation of the $p 53$ and mTOR pathways in cells. Proc Natl Acad Sci U S A. 2005;102(23):8204-9.

40. Webster GA, Perkins ND. Transcriptional cross talk between NF-kappaB and p53. Mol Cell Biol. 1999;19(5):3485-95.

41. Bensaad K, Tsuruta A, Selak MA, Vidal MN, Nakano K, Bartrons R, et al. TIGAR, a p53-inducible regulator of glycolysis and apoptosis. Cell. 2006;126(1):10720.

42. Wild-Bode C, Weller M, Rimner A, Dichgans J, Wick W. Sublethal irradiation promotes migration and invasiveness of glioma cells: implications for radiotherapy of human glioblastoma. Cancer Res. 2001;61(6):2744-50.

43. Pajonk F, Vlashi E, McBride WH. Radiation resistance of cancer stem cells: the 4 R's of radiobiology revisited. Stem Cells. 2010;28(4):639-48.

44. Dewhirst MW, Cao Y, Moeller B. Cycling hypoxia and free radicals regulate angiogenesis and radiotherapy response. Nat Rev Cancer. 2008;8(6):425-37.

45. Fornalski KW. Radiation adaptive response and cancer: from the statistical physics point of view. Phys Rev E. 2019;99(2-1):022139.

46. Alhajala HS, Nguyen HS, Shabani S, Best B, Kaushal M, Al-Gizawiy MM, et al. Irradiation of pediatric glioblastoma cells promotes radioresistance and enhances glioma malignancy via genome-wide transcriptome changes. Oncotarget. 2018:9(75):34122-31.

47. Bao S, Wu Q, McLendon RE, Hao Y, Shi Q, Hjelmeland AB, et al. Glioma stem cells promote radioresistance by preferential activation of the DNA damage response. Nature. 2006;444(7120):756-60.

48. De Pascalis I, Morgante L, Pacioni S, D'Alessandris QG, Giannetti S, Martini M, et al. Endothelial trans-differentiation in glioblastoma recurring after radiotherapy. Mod Pathol. 2018:31(9):1361-6.

49. Deshors P, Toulas C, Arnauduc F, Malric L, Siegfried A, Nicaise Y, et al. Ionizing radiation induces endothelial transdifferentiation of glioblastoma stem-like cells through the Tie2 signaling pathway. Cell Death Dis. 2019; 10(11):816.

50. Morgan MN, Dvuchbabny S, Martinez C-A, Kerr B, Cistulli PA, Cook KM. The cancer clock is (not) ticking: links between circadian rhythms and cancer. Clocks \&amp. Sleep. 2019;1(4):435-58.

51. Zhang R, Lahens NF, Ballance HI, Hughes ME, Hogenesch JB. A circadian gene expression atlas in mammals: implications for biology and medicine. Proc Natl Acad Sci. 2014;111(45):16219-24.

52. Fu L, Pelicano H, Liu J, Huang $P$, Lee $C$. The circadian gene Period2 plays an important role in tumor suppression and DNA damage response in vivo. Cell. 2002:111(1):41-50

53. Ye Y, Xiang Y, Ozguc FM, Kim Y, Liu C-J, Park PK, et al. The genomic landscape and Pharmacogenomic interactions of clock genes in cancer chronotherapy. Cell Systems. 2018;6(3):314-28.e2. 
54. Chen Z, Liu P, Li C. Yongluo, Chen I, Liang W, et al. deregulated expression of the clock genes in gliomas. Technol Cancer Res Treat. 2013;12(1):91-7.

55. Chang WH, Lai AG. Timing gone awry: distinct tumour suppressive and oncogenic roles of the circadian clock and crosstalk with hypoxia signalling in diverse malignancies. J Transl Med. 2019;17(1):132.

56. Wang F, Luo Y, Li C, Chen I. Correlation between deregulated expression of PER2 gene and Degree of glioma malignancy. Tumori Journal. 2014;100(6): 266-72.

57. Schernhammer ES, Laden F, Speizer FE, Willett WC, Hunter DJ, Kawachi I, et al. Rotating night shifts and risk of breast cancer in women participating in the Nurses' health study. JNCl: J Nat Cancer Institute. 2001;93(20):1563-8.

58. Papantoniou K, Castaño-Vinyals G, Espinosa A, Aragonés N, Pérez-Gómez B, Burgos J, et al. Night shift work, chronotype and prostate cancer risk in the MCC-Spain case-control study. Int J Cancer. 2015;137(5):1147-57.

59. Knutsson A, Alfredsson L, Karlsson B, Åkerstedt T, Fransson El, Westerholm P et al. Breast cancer among shift workers: results of the WOLF longitudinal cohort study. Scand J Work Environ Health. 2013;39(2):170-7.

60. Papagiannakopoulos T, Bauer Matthew R, Davidson Shawn M, Heimann M, Subbaraj L, Bhutkar A, et al. Circadian rhythm disruption promotes lung tumorigenesis. Cell Metab. 2016;24(2):324-31.

61. Kiessling S, Beaulieu-Laroche L, Blum ID, Landgraf D, Welsh DK, Storch K-F, et al. Enhancing circadian clock function in cancer cells inhibits tumor growth. BMC Biol. 2017;15(1):13.

62. Verlande A, Masri S. Circadian clocks and cancer: timekeeping governs cellular metabolism. Trends Endocrinol Metab. 2019;30(7):445-58.

63. Duhart JM, Brocardo L, Caldart CS, Marpegan L, Golombek DA. Circadian alterations in a murine model of hypothalamic glioma. Front Physiol. 2017;8: 864.

64. Madden MH, Anic GM, Thompson RC, Nabors LB, Olson JJ, Browning JE, et al. Circadian pathway genes in relation to glioma risk and outcome. Cancer Causes Control. 2014;25(1):25-32.

65. H-c X, Z-f N, Ma H, S-z C, S-c H, Z-t L, et al. Deregulated expression of the Per1 and Per2 in human gliomas. Canadian J Neurol Sci. 2010;37(3):365-70.

66. Yu M, Li W, Wang Q, Wang Y, Lu F. Circadian regulator NR1D2 regulates glioblastoma cell proliferation and motility. Oncogene. 2018;37(35):4838-53.

67. Luo YWF, Chen L-A, Chen X-W, Chen Z-J, Liu P-F, Li F-F, et al. Deregulated expression of Cry1 and Cry2 in human gliomas. Asian Pac J Cancer Prev. 2012;13(11):5725-8.

68. Khan S, Liu Y, Siddique R, Nabi G, Xue M, Hou H. Impact of chronically alternating light-dark cycles on circadian clock mediated expression of cancer (glioma)-related genes in the brain. Int J Biol Sci. 2019;15(9):1816-34.

69. Crespo I, Tão H, Nieto AB, Rebelo O, Domingues P, Vital AL, et al. Amplified and Homozygously deleted genes in glioblastoma: impact on gene expression levels. PLoS One. 2012;7(9):e46088.

70. Chen P, Hsu WH, Chang A, Tan Z, Lan Z, Zhou A, et al. Circadian regulator CLOCK recruits immune-suppressive microglia into the GBM tumor microenvironment. Cancer Discov. 2020;10(3):371-81.

71. Li A, Lin X, Tan X, Yin B, Han W, Zhao J, et al. Circadian gene clock contributes to cell proliferation and migration of glioma and is directly regulated by tumor-suppressive miR-124. FEBS Lett. 2013;587(15):2455-60.

72. Adamovich Y, Ladeuix B, Sobel J, Manella G, Neufeld-Cohen A, Assadi MH, et al. Oxygen and carbon dioxide rhythms are circadian clock controlled and differentially directed by behavioral signals. Cell Metab. 2019;29(5): 1092-103.e3.

73. Wu Y, Tang D, Liu N, Xiong W, Huang H, Li Y, et al. Reciprocal regulation between the circadian clock and hypoxia signaling at the genome level in mammals. Cell Metab. 2017:25(1):73-85.

74. Adamovich Y, Ladeuix B, Golik M, Koeners Maarten P, Asher G. Rhythmic oxygen levels reset circadian clocks through HIF1a. Cell Metab. 2017;25:93-101.

75. Peek CB, Levine DC, Cedernaes J, Taguchi A, Kobayashi Y, Tsai SJ, et al. Circadian clock interaction with HIF1a mediates oxygenic metabolism and anaerobic glycolysis in skeletal muscle. Cell Metab. 2017;25(1):86-92.

76. Yu C, Yang SL, Fang $X$, Jiang JX, Sun CY, Huang T. Hypoxia disrupts the expression levels of circadian rhythm genes in hepatocellular carcinoma. Mol Med Rep. 2015;11(5):4002-8.

77. Chilov D, Hofer T, Bauer C, Wenger RH, Gassmann M. Hypoxia affects expression of circadian genes PER1 and CLOCK in mouse brain. FASEB J. 2001;15(14):2613-22

78. Hogenesch JB, Gu Y-Z, Jain S, Bradfield CA. The basic-helix-loop-helix-PAS orphan MOP3 forms transcriptionally active complexes with circadian and hypoxia factors. Proc Natl Acad Sci. 1998;95(10):5474-9.
79. Walton ZE, Patel CH, Brooks RC, Yu Y, Ibrahim-Hashim A, Riddle M, et al. Acid suspends the circadian clock in hypoxia through inhibition of mTOR. Cell. 2018;174(1):72-87.e32.

80. Dimova EY, Jakupovic M, Kubaichuk K, Mennerich D, Chi TF, Tamanini F et al. The circadian clock protein CRY1 is a negative regulator of HIF-1a. iscience. 2019;13:284-304.

81. Kobayashi M, Morinibu A, Koyasu S, Goto Y, Hiraoka M, Harada H. A circadian clock gene, PER2, activates HIF-1 as an effector molecule for recruitment of HIF-1alpha to promoter regions of its downstream genes. FEBS J. 2017;284(22):3804-16.

82. Wang J, Mauvoisin D, Martin E, Atger F, Galindo AN, Dayon L, et al. Nuclear proteomics uncovers diurnal regulatory landscapes in mouse liver. Cell Metab. 2017;25(1):102-17.

83. Mure LS, Le HD, Benegiamo G, Chang MW, Rios L, Jillani N, et al. Diurnal transcriptome atlas of a primate across major neural and peripheral tissues. Science. 2018;359(6381):eaao0318.

84. Gerbes AL, Arbogast BJ. The influence of Timeshift on circadian rhythm of sensitivity to X-irradiation in mice. Chronobiol Int. 1984;1(3):177-84.

85. Kang T-H, Reardon JT, Kemp M, Sancar A. Circadian oscillation of nucleotide excision repair in mammalian brain. Proc Natl Acad Sci. 2009;106(8):2864-7.

86. Gaddameedhi S, Selby CP, Kaufmann WK, Smart RC, Sancar A. Control of skin cancer by the circadian rhythm. Proc Natl Acad Sci. 2011;108(46): 18790-5.

87. Xia HC, Wang F, Li YH, Li ZK, Cao SZ, Li CY, et al. The circadian gene expression of Per1 and Per2 and their influence on radiotherapeutic sensitivity of glioma in vitro. Future Neurol. 2012;7(3):341-8.

88. Zhanfeng N, Yanhui L, Zhou F, Shaocai H, Guangxing L, Hechun X. Circadian genes Per1 and Per2 increase radiosensitivity of glioma in vivo. Oncotarget. 2015;6(12):9951-8

89. Zhu L, Wang Q, Hu Y, Wang F. The circadian gene Per1 plays an important role in radiation-induced apoptosis and DNA damage in glioma. Asian Pac J Cancer Prev. 2019:20(7):2195-201.

90. Cui M, Xiao H, Luo D, Zhang X, Zhao S, Zheng Q, et al. Circadian rhythm shapes the gut microbiota affecting host Radiosensitivity. Int J Mol Sci. 2016; 17(11):1786

91. Johnson K, Chang-Claude J, Critchley AM, Kyriacou C, Lavers S, Rattay T, et al. Genetic variants predict optimal timing of radiotherapy to reduce side-effects in breast cancer patients. Clin Oncol. 2019;31(1):9-16.

92. Chan S, Zhang L, Rowbottom L, McDonald R, Bjarnason GA, Tsao M, et al. Effects of circadian rhythms and treatment times on the response of radiotherapy for painful bone metastases. Ann Palliative Med. 2016;6(1):14-25.

93. Chan S, Rowbottom L, McDonald R, Zhang L, Bjarnason GA, Tsao M, et al. Could time of whole brain radiotherapy delivery impact overall survival in patients with multiple brain metastases? Ann Palliative Med. 2016:5(4):267-79

94. Noh JM, Choi DH, Park H, Huh SJ, Park W, Seol SW, et al. Comparison of acute skin reaction following morning versus late afternoon radiotherapy in patients with breast cancer who have undergone curative surgical resection. J Radiat Res. 2014:55(3):553-8.

95. Rahn DA III, Ray DK, Schlesinger DJ, Steiner L, Sheehan JP, O'Quigley JM, et al. Gamma knife radiosurgery for brain metastasis of nonsmall cell lung cancer: is there a difference in outcome between morning and afternoon treatment? Cancer. 2011:117(2):414-20.

96. Badiyan SN, Ferraro DJ, Yaddanapudi S, Drzymala RE, Lee AY, Silver SA, et al. Impact of time of day on outcomes after stereotactic radiosurgery for nonsmall cell lung cancer brain metastases. Cancer. 2013;119(19):3563-9.

97. Bjarnason GA, MacKenzie RG, Nabid A, Hodson ID, El-Sayed S, Grimard L, et al. Comparison of toxicity associated with early morning versus late afternoon radiotherapy in patients with head-and-neck cancer: a prospective randomized trial of the National Cancer Institute of Canada clinical trials group (HN3). Int J Radiation Oncol*Biology*Physics. 2009;73(1): 166-72.

98. Goyal M, Shukla P, Gupta D, Bisht SS, Dhawan A, Gupta S, et al. Oral mucositis in morning vs. evening irradiated patients: a randomised prospective study. Int J Radiat Biol. 2009;85(6):504-9.

99. Shukla P, Gupta D, Bisht SS, Pant MC, Bhatt ML, Gupta R, et al. Circadian variation in radiation-induced intestinal mucositis in patients with cervical carcinoma. Cancer. 2010;116(8):2031-5.

100. Hsu F-M, Hou W-H, Huang C-Y, Wang C-C, Tsai C-L, Tsai Y-C, et al. Differences in toxicity and outcome associated with circadian variations 
between patients undergoing daytime and evening radiotherapy for prostate adenocarcinoma. Chronobiol Int. 2016;33(2):210-9.

101. Eckel-Mahan Kristin L, Patel Vishal R, de Mateo S, Orozco-Solis R, Ceglia Nicholas J, Sahar S, et al. Reprogramming of the circadian clock by nutritional challenge. Cell. 2013;155(7):1464-78.

102. Kohsaka A, Laposky AD, Ramsey KM, Estrada C, Joshu C, Kobayashi Y, et al. High-fat diet disrupts behavioral and molecular circadian rhythms in mice. Cell Metab. 2007;6(5):414-21.

103. Vollmers C, Gill S, DiTacchio L, Pulivarthy SR, Le HD, Panda S. Time of feeding and the intrinsic circadian clock drive rhythms in hepatic gene expression. Proc Natl Acad Sci. 2009;106(50):21453-8.

104. Damiola F, Le Minh N, Preitner N, Kornmann B, Fleury-Olela F, Schibler U. Restricted feeding uncouples circadian oscillators in peripheral tissues from the central pacemaker in the suprachiasmatic nucleus. Genes Dev. 2000; 14(23):2950-61.

105. Stokkan K-A, Yamazaki S, Tei H, Sakaki Y, Menaker M. Entrainment of the circadian clock in the liver by feeding. Science. 2001;291(5503):490-3.

106. Shamsi NA, Salkeld MD, Rattanatray L, Voultsios A, Varcoe TJ, Boden MJ, et al. Metabolic consequences of timed feeding in mice. Physiol Behav. 2014;128:188-201.

107. Dallmann R, Viola AU, Tarokh L, Cajochen C, Brown SA. The human circadian metabolome. Proc Natl Acad Sci. 2012;109(7):2625-9.

108. Sato S, Parr EB, Devlin BL, Hawley JA, Sassone-Corsi P. Human metabolomics reveal daily variations under nutritional challenges specific to serum and skeletal muscle. Mol Metab. 2018:16:1-11.

109. Kettner NM, Voicu H, Finegold MJ, Coarfa C, Sreekumar A, Putluri N, et al. Circadian homeostasis of liver metabolism suppresses Hepatocarcinogenesis. Cancer Cell. 2016;30(6):909-24.

110. Guerrero-Vargas NN, Navarro-Espíndola R, Guzmán-Ruíz MA, MdC B, EspitiaBautista E, López-Bago A, et al. Circadian disruption promotes tumor growth by anabolic host metabolism; experimental evidence in a rat model. BMC Cancer. 2017;17(1):625.

111. Zheng H, Ying H, Yan H, Kimmelman AC, Hiller DJ, Chen A-J, et al. Pten and p53 converge on c-Myc to control differentiation, self-renewal, and transformation of Normal and neoplastic stem cells in glioblastoma. Cold Spring Harb Symp Quant Biol. 2008;73:427-37.

112. Tateishi K, lafrate AJ, Ho Q, Curry WT, Batchelor TT, Flaherty KT, et al. Mycdriven glycolysis is a therapeutic target in glioblastoma. Clin Cancer Res. 2016;22(17):4452-65.

113. Wang Y, Song L, Liu M, Ge R, Zhou Q, Liu W, et al. A proteomics landscape of circadian clock in mouse liver. Nat Commun. 2018;9(1): 1553.

114. Altman Brian J, Hsieh Annie L, Sengupta A, Krishnanaiah Saikumari Y, Stine Zachary E, Walton Zandra E, et al. MYC disrupts the circadian clock and metabolism in cancer cells. Cell Metab. 2015;22(6):1009-19.

115. Huber A-L, Papp SJ, Chan AB, Henriksson E, Jordan SD, Kriebs A, et al. CRY2 and FBXL3 cooperatively degrade c-MYC. Mol Cell. 2016;64(4):774-89.

116. Zheng $X$, Sehgal A. AKT and TOR signaling set the pace of the circadian pacemaker. Curr Biol. 2010;20(13):1203-8.

117. Szabó A, Papin C, Cornu D, Chélot E, Lipinszki Z, Udvardy A, et al. Ubiquitylation dynamics of the clock cell proteome and TIMELESS during a circadian cycle. Cell Rep. 2018;23(8):2273-82.

118. Baker LC, Boult JK, Walker-Samuel S, Chung YL, Jamin Y, Ashcroft M, et al. The HIF-pathway inhibitor NSC-134754 induces metabolic changes and anti-tumour activity while maintaining vascular function. Br J Cancer. 2012; 106(10):1638-47.

119. Cairns RA, Papandreou I, Sutphin PD, Denko NC. Metabolic targeting of hypoxia and HIF1 in solid tumors can enhance cytotoxic chemotherapy. Proc Natl Acad Sci U S A. 2007;104(22):9445-50.

120. Trachootham D, Alexandre J, Huang P. Targeting cancer cells by ROSmediated mechanisms: a radical therapeutic approach? Nat Rev Drug Discov. 2009;8(7):579-91.

121. Benej M, Hong X, Vibhute S, Scott S, Wu J, Graves E, et al. Papaverine and its derivatives radiosensitize solid tumors by inhibiting mitochondrial metabolism. Proc Natl Acad Sci U S A. 2018;115(42):10756-61.

122. Kilic-Eren M, Boylu T, Tabor V. Targeting PI3K/Akt represses hypoxia inducible factor-1alpha activation and sensitizes rhabdomyosarcoma and Ewing's sarcoma cells for apoptosis. Cancer Cell Int. 2013;13:36.

123. Wardman P. Chemical radiosensitizers for use in radiotherapy. Clin Oncol (R Coll Radiol). 2007;19(6):397-417.
124. Wilson WR, Hay MP. Targeting hypoxia in cancer therapy. Nat Rev Cancer. 2011;11(6):393-410.

125. Mason RP, Holtzman JL. The role of catalytic superoxide formation in the $\mathrm{O} 2$ inhibition of nitroreductase. Biochem Biophys Res Commun. 1975;67(4): 1267-74.

126. Kappen LS, Lee TR, Yang CC, Goldberg $\mathbb{H}$. Oxygen transfer from the nitro group of a nitroaromatic radiosensitizer to a DNA sugar damage product. Biochemistry. 1989;28(11):4540-2.

127. Urtasun R, Feldstein ML, Partington J, Tanasichuk H, Miller JD, Russell DB, et al. Radiation and nitroimidazoles in supratentorial high grade gliomas: a second clinical trial. Br J Cancer. 1982;46(1):101-8.

128. Dische $\mathrm{S}$. Chemical sensitizers for hypoxic cells: a decade of experience in clinical radiotherapy. Radiother Oncol. 1985;3(2):97-115.

129. Urtasun RC, Palmer M, Kinney B, Belch A, Hewitt J, Hanson J. Intervention with the hypoxic tumor cell sensitizer etanidazole in the combined modality treatment of limited stage small-cell lung cancer. A one-institution study. Int J Radiat Oncol Biol Phys. 1998;40(2):337-42.

130. Overgaard J, Horsman MR. Modification of hypoxia-induced Radioresistance in tumors by the use of oxygen and sensitizers. Semin Radiat Oncol. 1996; 6(1):10-21.

131. Overgaard J, Hansen HS, Overgaard M, Bastholt L, Berthelsen A, Specht L, et al. A randomized double-blind phase III study of nimorazole as a hypoxic radiosensitizer of primary radiotherapy in supraglottic larynx and pharynx carcinoma. Results of the Danish head and neck cancer study (DAHANCA) protocol 5-85. Radiother Oncol. 1998:46(2):135-46.

132. Hunter FW, Hsu HL, Su J, Pullen SM, Wilson WR, Wang J. Dual targeting of hypoxia and homologous recombination repair dysfunction in triplenegative breast cancer. Mol Cancer Ther. 2014;13(11):2501-14.

133. Brenner A, Zuniga R, Sun JD, Floyd J, Hart CP, Kroll S, et al. Hypoxiaactivated evofosfamide for treatment of recurrent bevacizumab-refractory glioblastoma: a phase I surgical study. Neuro-Oncology. 2018;20(9):1231-9.

134. Dorie MJ, Menke D, Brown JM. Comparison of the enhancement of tumor responses to fractionated irradiation by SR 4233 (tirapazamine) and by nicotinamide with carbogen. Int J Radiat Oncol Biol Phys. 1994;28(1):145-50.

135. Shulman LN, Buswell L, Riese N, Doherty N, Loeffler JS, von Roemeling RW, et al. Phase I trial of the hypoxic cell cytotoxin tirapazamine with concurrent radiation therapy in the treatment of refractory solid tumors. Int J Radiat Oncol Biol Phys. 1999:44(2):349-53.

136. Del Rowe J, Scott C, Werner-Wasik M, Bahary JP, Curran WJ, Urtasun RC, et al. Single-arm, open-label phase II study of intravenously administered tirapazamine and radiation therapy for glioblastoma multiforme. J Clin Oncol. 2000;18(6):1254-9.

137. Floridi A, Paggi MG, Marcante ML, Silvestrini B, Caputo A, De Martino C. Lonidamine, a selective inhibitor of aerobic glycolysis of murine tumor cells. J Natl Cancer Inst. 1981;66(3):497-9.

138. Carapella CM, Paggi MG, Calvosa F, Cattani F, Jandolo B, Mastrostefano R, et al. Lonidamine in the combined treatment of malignant gliomas. A randomized study. J Neurosurg Sci. 1990;34(3-4):261-4.

139. Laszlo J, Humphreys SR, Goldin A. Effects of glucose analogues (2-deoxy-Dglucose, 2-deoxy-D-galactose) on experimental tumors. J Natl Cancer Inst. 1960;24:267-81.

140. Jain VK, Kalia VK, Sharma R, Maharajan V, Menon M. Effects of 2-deoxy-Dglucose on glycolysis, proliferation kinetics and radiation response of human cancer cells. Int J Radiat Oncol Biol Phys. 1985;11(5):943-50.

141. Kaplan O, Navon G, Lyon RC, Faustino PJ, Straka EJ, Cohen JS. Effects of 2deoxyglucose on drug-sensitive and drug-resistant human breast cancer cells: toxicity and magnetic resonance spectroscopy studies of metabolism. Cancer Res. 1990;50(3):544-51.

142. Shah SS, Rodriguez GA, Musick A, Walters WM, de Cordoba N, Barbarite E, et al. Targeting glioblastoma stem cells with 2-deoxy-D-glucose (2-DG) potentiates radiation-induced unfolded protein response (UPR). Cancers (Basel). 2019;11(2):159

143. Dwarakanath BS, Jain VK. Modification of the radiation induced damage by 2-deoxy-D-glucose in organ cultures of human cerebral gliomas. Int J Radiat Oncol Biol Phys. 1987;13(5):741-6.

144. Heminger K, Jain V, Kadakia M, Dwarakanath B, Berberich SJ. Altered gene expression induced by ionizing radiation and glycolytic inhibitor 2-deoxyglucose in a human glioma cell line: implications for radio sensitization. Cancer Biol Ther. 2006;5(7):815-23.

145. Singh D, Banerij AK, Dwarakanath BS, Tripathi RP, Gupta JP, Mathew TL, et al. Optimizing cancer radiotherapy with 2-deoxy-d-glucose dose 
escalation studies in patients with glioblastoma multiforme. Strahlenther Onkol. 2005:181(8):507-14.

146. Dwarakanath BS, Singh D, Banerji AK, Sarin R, Venkataramana NK, Jalali $R$, et al. Clinical studies for improving radiotherapy with 2-deoxy-Dglucose: present status and future prospects. J Cancer Res Ther. 2009; 5(Suppl 1):S21-6.

147. Chang JM, Chung JW, Jae HJ, Eh H, Son KR, Lee KC, et al. Local toxicity of hepatic arterial infusion of hexokinase II inhibitor, 3-bromopyruvate: in vivo investigation in normal rabbit model. Acad Radiol. 2007;14(1):85-92.

148. Kunjithapatham R, Geschwind JF, Rao PP, Boronina TN, Cole RN, GanapathyKanniappan S. Systemic administration of 3-bromopyruvate reveals its interaction with serum proteins in a rat model. BMC Res Notes. 2013;6:277.

149. Stacpoole PW. Therapeutic targeting of the pyruvate dehydrogenase complex/pyruvate dehydrogenase kinase (PDC/PDK) Axis in cancer. J Natl Cancer Inst. 2017:109(11).

150. Abildgaard C, Dahl C, Basse AL, Ma T, Guldberg P. Bioenergetic modulation with dichloroacetate reduces the growth of melanoma cells and potentiates their response to BRAFV600E inhibition. J TransI Med. 2014;12: 247.

151. Ruggieri V, Agriesti F, Scrima R, Laurenzana I, Perrone D, Tataranni T, et al. Dichloroacetate, a selective mitochondria-targeting drug for oral squamous cell carcinoma: a metabolic perspective of treatment. Oncotarget. 2015;6(2); 1217-30.

152. Shavit R, llouze M, Feinberg T, Lawrence YR, Tzur Y, Peled N. Mitochondrial induction as a potential radio-sensitizer in lung cancer cells - a short report. Cell Oncol. 2015:38(3):247-52

153. Cao W, Yacoub S, Shiverick KT, Namiki K, Sakai Y, Porvasnik S, et al. Dichloroacetate (DCA) sensitizes both wild-type and over expressing Bcl-2 prostate cancer cells in vitro to radiation. Prostate. 2008;68(11):1223-31.

154. Zwicker F, Kirsner A, Peschke P, Roeder F, Debus J, Huber PE, et al. Dichloroacetate induces tumor-specific radiosensitivity in vitro but attenuates radiation-induced tumor growth delay in vivo. Strahlenther Onkol. 2013:189(8):684-92.

155. Shen H, Hau E, Joshi S, Dilda PJ, McDonald KL. Sensitization of glioblastoma cells to irradiation by modulating the glucose metabolism. Mol Cancer Ther. 2015;14(8):1794-804

156. Shen H, Yu M, Tsoli M, Chang C, Joshi S, Liu J, et al. Targeting reduced mitochondrial DNA quantity as a therapeutic approach in pediatric highgrade gliomas. Neuro-Oncology. 2019

157. Dunbar EM, Coats BS, Shroads AL, Langaee T, Lew A, Forder JR, et al. Phase 1 trial of dichloroacetate (DCA) in adults with recurrent malignant brain tumors. Invest New Drugs. 2014;32(3):452-64.

158. Michelakis ED, Sutendra G, Dromparis P, Webster L, Haromy A, Niven E, et al. Metabolic modulation of glioblastoma with dichloroacetate. Sci Transl Med. 2010;2(31):31ra4.

159. Abdelmalak M, Lew A, Ramezani R, Shroads AL, Coats BS, Langaee T, et al. Long-term safety of dichloroacetate in congenital lactic acidosis. Mol Genet Metab. 2013;109(2):139-43.

160. Reiter RJ, Sharma R, Ma Q, Rorsales-Corral S, de Almeida Chuffa LG. Melatonin inhibits Warburg-dependent cancer by redirecting glucose oxidation to the mitochondria: a mechanistic hypothesis. Cell Mol Life Sci. 2020;77(13):2527-42.

161. Alonso-Gonzalez C, Gonzalez A, Martinez-Campa C, Menendez-Menendez J, Gomez-Arozamena J, Garcia-Vidal A, et al. Melatonin enhancement of the radiosensitivity of human breast cancer cells is associated with the modulation of proteins involved in estrogen biosynthesis. Cancer Lett. 2016; 370(1):145-52

162. Chuffa L, Seiva F, Cucielo M, Silveira H, Reiter RJ, Lupi LA. Clock genes and the role of melatonin in cancer cells: an overview. Melatonin Research. 2019;2:133-57.

163. Colombo J, Maciel JM, Ferreira LC, DAS RF, Zuccari DA. Effects of melatonin on HIF-1alpha and VEGF expression and on the invasive properties of hepatocarcinoma cells. Oncol Lett. 2016;12(1):231-7.

164. Sulli G, Rommel A, Wang X, Kolar MJ, Puca F, Saghatelian A, et al. Pharmacological activation of REV-ERBs is lethal in cancer and oncogeneinduced senescence. Nature. 2018;553(7688):351-5.

165. Harper E, Talbot CJ. Is it time to change radiotherapy: the dawning of Chronoradiotherapy? Clin Oncol (R Coll Radiol). 2019;31(5):326-35.

\section{Publisher's Note}

Springer Nature remains neutral with regard to jurisdictional claims in published maps and institutional affiliations.

Ready to submit your research? Choose BMC and benefit from:

- fast, convenient online submission

- thorough peer review by experienced researchers in your field

- rapid publication on acceptance

- support for research data, including large and complex data types

- gold Open Access which fosters wider collaboration and increased citations

- maximum visibility for your research: over $100 \mathrm{M}$ website views per year

At BMC, research is always in progress.

Learn more biomedcentral.com/submissions 